\section{Should Developed Countries, Including Canada, Provide Universal Access to Essential Medications through a National, Publicly Funded and Administered Insurance Plan?}

\section{THE "PRO" SIDE}

Canada is currently the only developed country with a universal health care system that does not provide universal coverage for prescription medications. ${ }^{1}$ Implementation of a national drug insurance program would give Canadians universal access to necessary medicines, ensure fair distribution of prescription drug costs, encourage safe and appropriate prescribing, and provide maximum cost-effectiveness for drugs.

\section{Definitions}

The national pharmacare program that we envision is 2-tiered: a public plan would provide drug coverage for essential medications, and private plans would cover nonessential medications. According to the World Health Organization, universal access is defined as availability of affordable medications at facilities within 1 hour's walk from home. ${ }^{2}$ Medications that satisfy priority health care needs and concerns are classified as essential medications. ${ }^{3}$

\section{Universal Access and Equitability}

Canada is well known for its universal public health program, as mandated by the Canada Health Act. ${ }^{4,5}$ This legislation dictates that 5 criteria be met in provincially administered public health care insurance plans: public administration, comprehensiveness, universality, portability, and accessibility. ${ }^{5,6}$ These criteria are currently met by required medical services. ${ }^{5}$ In contrast, Canadian coverage for outpatient drugs is a patchwork of public and private drug insurance plans providing coverage that is, unfortunately, neither universal nor comprehensive. ${ }^{7}$ Indeed, $10 \%$ of Canadians cannot afford their prescribed medications. ${ }^{8}$

Moreover, the current system lacks equitability. The criteria for drug coverage vary across provinces. For example, drugs are covered on the basis of income in British Columbia, whereas age is the major determinant in Ontario. ' The ability to afford medications should not be driven by age, income, or geographic location.
A national pharmacare program would ensure that all Canadians receive consistent, coast-to-coast coverage for essential medications and that the tenets of the Canada Health Act are upheld.

\section{Safer Prescribing Practices and a National Database}

Implementation of a national pharmacare program would promote safe, effective, and evidence-based drug prescribing. Currently, the innumerable private and public drug plans in Canada are not coordinated. ${ }^{1}$ Private plans often cover medications that lack evidence of favourable risk-benefit ratios. ${ }^{1}$ This situation poses a concern for prescribers, who may be forced to prescribe suboptimal therapies in an effort to ensure affordability through private plans. Prescribing should be dictated by the safety and efficacy of drugs, not by their cost. A 2006 study from a Canadian hospital showed that more appropriate prescribing could have prevented over $70 \%$ of admissions. ${ }^{10}$ Having a single, national, evidence-based formulary would guide prescribing habits and would be integral in ensuring safe and cost-effective medication use.

Furthermore, a pharmacare program would logically provide the basis for developing a national drug-related monitoring database. ${ }^{1}$ Currently, health care databases are controlled independently by governments, pharmacy retailers, and private insurance companies. ${ }^{1}$ Because of this fragmented system, Canada lacks quality surveillance of prescribing practices and related health outcomes. ${ }^{1}$ A national database would provide insight into medication safety and efficacy, and thereby aid in determining areas for improvement of prescribing practices.

\section{Economic Benefits}

A national pharmacare strategy would be both economically feasible and beneficial. In 2015, Morgan and others ${ }^{11}$ published an analysis modelling a national, publicly funded and administered health insurance system for Canada. These authors found that, although government costs could increase by about $\$ 1$ billion, the projected combined cost savings from private and public sectors would be substantial, ranging from $\$ 4.2$ billion to $\$ 9.4$ billion in the worst-case and best-case scenarios, respectively. ${ }^{11}$ The analysis accounted for increased usage of medications with universal drug coverage, transfer of private sector costs to the public sector, cost-effective product selection with a national formulary, and consolidation of drug purchasing power. ${ }^{11}$ 
While the study by Morgan and others ${ }^{11}$ accounted only for direct cost savings, it is expected that a national pharmacare strategy would have indirect economic benefits as well. First, improved prescribing practices with guidance by a national formulary would reduce drug-related adverse reactions and hospital admissions, resulting in up to $\$ 5$ billion in cost savings. ${ }^{1}$ Second, because each province currently manages its own health insurance plan, an estimated $\$ 1$ billion to $\$ 2$ billion would be saved in administration costs through consolidation to a single, national plan. ${ }^{1}$ Finally, improved adherence to previously unaffordable medications would produce $\$ 1$ billion to $\$ 9$ billion in financial savings through better management of preventable diseases, ${ }^{12}$ as well as cost savings related to decreased absenteeism and increased productivity at work.

Therefore, the additional costs to the government incurred by implementing a national pharmacare program would be offset by major direct and indirect financial savings. In addition to providing universal drug coverage to Canadians, the program would improve the economy on a national level.

\section{Successes of Other Countries}

Implementing national pharmacare in Canada may appear to be a challenging objective, but the successes of other developed countries with national drug coverage provide evidence that it would be both feasible and economically beneficial. Examples include the United Kingdom and New Zealand.

Financed primarily by general taxation, the UK health care plan grants universal coverage of select drugs as outlined in a national drug formulary. ${ }^{13}$ Using this system, the United Kingdom has lowered costs for prescription drugs through better pricing and reduced overprescribing, ultimately spending the same percentage of the world market share for prescription drugs as Canada, despite having twice the Canadian population. ${ }^{14}$

New Zealand also provides universal drug coverage to permanent residents, which is financed through general taxes. ${ }^{14}$ The Pharmaceutical Management Agency (PHARMAC) determines the national drug formulary and negotiates drug prices on behalf of the entire country. ${ }^{13,14}$ Through PHARMAC's efforts, prescription costs have been kept low. One study found that for 4 large classes of prescription drugs, New Zealand paid 51\% less than British Columbia. ${ }^{15}$

\section{Conclusion}

These comparisons of Canada with the United Kingdom and New Zealand make it clear that not only does Canada's patchwork of drug insurance fail to provide equitable access to medications, but it also does the country no favours with regard to financial considerations. With a strict formulary in place and with an expected increase in buying power, implementation of a national pharmacare program would be economically advantageous and would allow Canada to join the ranks of developed countries that provide truly universal health care.

\section{References}

1. Morgan SG, Martin D, Gagnon MA, Mintzes B, Daw JR, Lexchin J. Pharmacare 2020: the future of drug coverage in Canada. Vancouver (BC): University of British Columbia, Pharmaceutical Policy Research Collaboration; 2015 [cited 2015 Nov 12]. Available from: http:// pharmacare2020.cal

2. MDG Gap Task Force. Access to affordable essential medicines. In: The MDG Gap Task Force report 2008-delivering on the global partnership for achieving the millennium development goals. New York (NY): United Nations Publications; 2008. p. 35-44.

3. Essential medicines and health products: essential medicines. Geneva (Switzerland): World Health Organization; 2016 [cited 2015 Nov 8]. Available from: www.who.int/medicines/services/essmedicines_def/en/

4. Boslaugh SE. Health care systems around the world: a comparative guide. Thousand Oaks (CA): Sage Publications; 2013.

5. Madore O. The Canada Health Act: overview and options. Ottawa $(\mathrm{ON})$ : Parliament of Canada; 2005 [cited 2015 Nov 16]. Available from: www.parl.gc.ca/content/lop/researchpublications/944-e.htm

6. Canada Health Act, R.S.C. 1965, c. C-6 [cited 2015 Nov 16]. Available from: http://laws-lois.justice.gc.ca/eng/acts/c-6/

7. Law MR, Cheng L, Dhalla IA, Heard D, Morgan SG. The effect of cost on adherence to prescription medications in Canada. CMAJ. 2012;184(3): 297-302.

8. Morgan S. Four things needed to make pharmacare work for Canadians. Winnipeg (MB): Evidence Network.ca; [cited 2015 Dec 17]. Available from: http://umanitoba.ca/outreach/evidencenetwork/archives/23781

9. Busby C, Pedde J. Should public drug plans be based on age or income? Commentary no. 417. Toronto (ON): C.D. Howe Institute; 2014 [cited 2015 Nov 14]. Available from: https://www.cdhowe.org/pdf/ Commentary_417.pdf

10. Samoy LJ, Zed PJ, Wilbur K, Balen RM, Abu-Laban RB, Roberts M. Drugrelated hospitalizations in a tertiary care internal medicine service of a Canadian hospital: a prospective study. Pharmacotherapy. 2006;26(11):1578-86.

11. Morgan SG, Law M, Daw JR, Abraham L, Martin D. Estimated cost of universal public coverage of prescription drugs in Canada. CMAJ. 2015; 187(7):491-7.

12. Clinical service proposal. Medication adherence services. Vancouver (BC): British Columbia Pharmacy Association; 2013 [cited 2015 Dec 15]. Available from: www.bcpharmacy.ca/uploads/Medication_Adherence.pdf

13. Mossialos E, Wenzl M, Osborn R, Anderson C, editors. International profiles of health care systems, 2014. New York (NY): The Commonwealth Fund; 2015.

14. Milne V, Laupacis A, Tierney M. Prescription drug coverage: How does Canada compare? Toronto (ON): HealthyDebate.ca; 2015 [cited 2015 Dec 16]. Available from: http://healthydebate.ca/2015/03/topic/pharmacare-2

15. Morgan S, Hanley G, Mcmahon M, Barer M. Influencing drug prices through formulary-based policies: lessons from New Zealand. Healthc Policy. 2007;3(1):e121-40.
Rajwant Minhas, BSc(Pharm), ACPR

Joan Chung Yan Ng, BSC(Pharm), ACPR

Jason Tan, BSc(Pharm), ACPR

Hilary Wu, BSc(Pharm), ACPR

Doctor of Pharmacy (Graduate) students

Sarah Stabler, BSC(Pharm), ACPR, PharmD

Clinical Instructor

Faculty of Pharmaceutical Sciences

University of British Columbia

Vancouver, British Columbia

Sarah Stabler is also a Clinical Pharmacy Specialist (Critical Care) with Surrey Memorial Hospital, Surrey, British Columbia.

Competing interests: None declared. 


\section{THE "CON" SIDE}

A unified, single-payer insurance plan that provides universal access to medications seems like an ethically sound and fundamentally Canadian program to have. However, when the evidence for implementing such a program is critically examined, doubt arises about its ability to achieve the overarching goal of improving access to medications while minimizing cost to taxpayers.

A frequently cited rationale for a national drug plan is cost savings. ${ }^{1}$ In a report published recently in the CMAJ, Morgan and others $^{2}$ estimated a cost savings of $\$ 7.3$ billion annually. When interpreted at a superficial level, this theoretical reduction in prescription drug spending with implementation of a national drug plan appears attractive ${ }^{2}$, however, there are several limitations to this estimate. Morgan and others ${ }^{2}$ created a model that suggested $\$ 4.2$ billion to $\$ 9.4$ billion would be saved if their projections were accurate. The total cost of prescriptions was based on the volume of prescriptions purchased, the products selected, and the prices paid for these products. ${ }^{2}$ As the authors admitted, it is difficult to simulate how these parameters would change with the institution of universal drug coverage. ${ }^{2}$ Despite the expertise of the study authors in the area of health economics, the estimation of cost savings from this model is not purely objective math; a degree of subjectivity is required when deciding the amount of variation to assume within these parameters after theoretical application of a national drug plan. This approach becomes somewhat problematic, as the 3 papers cited in the $C M A J$ article $^{2}$ as the sources for modelling this variation were all written solely by Morgan, who is an outspoken proponent of universal drug coverage. This subjectivity, along with the challenges of accurately modelling future prescription drug costs in a system with an entirely different payment structure, should prompt cautious interpretation of large cost-savings figures.

Successful national drug plans, such as New Zealand's, are able to decrease drug expenditure by negotiating lower drug pricing from manufacturers. Thus, proponents of a national drug plan suggest that unified national negotiating power will reduce costs. However, Canada already has an avenue by which this is achieved: the pan-Canadian Pharmaceutical Alliance. ${ }^{3}$ Through this initiative, provinces and territories are able to negotiate savings on both brand and generic drug costs. This initiative saves an estimated $\$ 490$ million dollars annually on drug costs for Canadians. ${ }^{3}$

Given that Canada already has a system in place to negotiate the cost of prescription drugs, the main alternative to reduce spending is to institute a more restrictive formulary. This type of model would face backlash from patients, prescribers, and advocacy groups that would no longer receive drug funding for treatments that were previously covered under provincial plans. For universal drug coverage to achieve meaningful cost savings, a unified, more restrictive formulary would need to be instituted, and this would decrease accessibility to medications for Canadians.
Supporters of a national drug plan argue that it would improve access to prescription drugs for patients with low incomes. ${ }^{1}$ However, a study published by the Commonwealth Fund in 2014 reported that $8 \%$ of Canadians with below-average incomes had not filled a prescription or had skipped doses because of cost. ${ }^{4}$ This figure mirrors that of Germany ( $\left.8 \%\right)$ and is less than those of France (11\%), Australia (14\%), and New Zealand $(18 \%), 4,5$ which suggests that Canadians do not experience significant cost barriers preventing them from adhering to medications, relative to citizens of countries that have national drug coverage programs.

Proponents of a national drug coverage plan also suggest that immediate cost barriers (e.g., copayments and deductibles) would be decreased with a national pharmacare plan. ${ }^{1}$ However, countries with this type of plan do not fully cover out-of-pocket expenses, and Canadians would continue to pay these costs, as they do under current provincially delivered plans. For example, out-of-pocket expenses represent more than $30 \%$ of total spending in Australia, Norway, and New Zealand-all countries with national pharmacare plans. ${ }^{6}$ This proportion is comparable to that in Canada, where out-of-pocket expenses are $25 \%$, less than the aforementioned countries. ${ }^{6}$

Those in favour of a national drug coverage plan acknowledge that private insurance plans would need to remain as integral payers for medications. It is simply not feasible to abolish private insurance altogether; for example, in 2013, private insurers accounted for $\$ 10.1$ billion of prescription drug expenditure in Canada (the public sector accounted for $\$ 12.1$ billion). ${ }^{7}$ The private insurance industry, in which the consumer pays for the service, is robust and sustainable. However, a national pharmacare system coexisting with private insurance plans would be counterproductive to the goals of a national insurance program. Medicines would not be equally accessible to all Canadians, and the proclaimed undesirable "patchwork" of insurance programs would persist.

Another important question to answer is whether the federal government is an appropriate entity to deliver this aspect of health care. Since the Canada Health Act was passed in 1984, the provinces and territories have been administering and delivering the majority of Canada's health care services. ${ }^{8}$ It does not seem appropriate to give the federal government responsibility for drug coverage when the provinces are responsible for funding hospitals, physicians, and other personnel and medical services. In a survey performed in 2015 on the topic of national pharmacare, $85 \%$ of respondents stated that they were concerned about the federal government's ability to administer the proposed plan efficiently and effectively. ${ }^{9}$

A national drug plan would add complexity to the current system, without offering a substantial benefit. Projections of cost savings to consumers, and the country as a whole, are flawed and are unlikely to be realized with such an enormous consolidation 
of essential services. Provincial governments are experienced in delivering drug coverage plans tailored to their populations' specific needs, and flexibility within the current system allows for a sustainable combination of public and private payers for medications. In practice, Canadians already experience the best aspects of a national drug coverage plan; the formal institution of such a plan will only increase bureaucracy and complicate delivery of services, without adding value for patients.

\section{References}

1. Morgan SG, Martin D, Gagnon MA, Mintzes B, Daw JR, Lexchin J. Pharmacare 2020: the future of drug coverage in Canada. Vancouver (BC): University of British Columbia, Pharmaceutical Policy Research Collaboration; 2015.

2. Morgan SG, Law M, Daw JR, Abraham L, Martin D. Estimated cost of universal public coverage of prescription drugs in Canada. CMAJ. 2015;187(7):491-7.

3. The pan-Canadian pharmaceutical alliance. Ottawa $(\mathrm{ON})$ : Council of the Federation Secretariat; 2013 [cited 2015 Dec 14]. Available from: www. pmprovincesterritoires.ca/en/initiatives/358-pan-canadian-pharmaceutical-alliance

4. Davis K, Stremikis K, Squires D, Schoen C. Mirror, mirror on the wall: how the performance of the U.S. health care system compares internationally. New York (NY): The Commonwealth Fund; 2014.

5. Labrie Y. Do we need a public drug insurance monopoly in Canada? Economic note explaining the advantages of having a mixed public-private drug insurance system. Montréal (QC): Montreal Economic Institute; 2015 [cited 2015 Dec 14]. Available from: www.iedm.org/54639-do-we-need-a-public-druginsurance-monopoly-in-canada

6. Organisation for Economic Co-operation and Development. Health at a glance 2011: OECD indicators. Paris (France): OECD Publishing; 2011.

7. Prescribed drug spending in Canada, 2012: a focus on public drug programs.
Ottawa (ON): Canadian Institute for Health Information; 2014.

8. Canada's health care system. Ottawa (ON): Health Canada; [updated 2012 Oct 9; cited 2015 Dec 14]. Available from: www.hc-sc.gc.ca/hcs-sss/pubs/ system-regime/2011-hcs-sss/index-eng.php

9. National pharmacare in Canada: a survey of Canadian attitudes towards developing a national pharmacare program. Ottawa (ON): Abacus Data; 2015 Jul [cited 2015 Dec 14]. Available from: www.pharmacists.ca/cpha-ca/ assets/File/pharmacy-in-canada/Pharmacare\%20Survey\%20Results_ July\%202015.pdf

Jessica Beach, BSC(Pharm), ACPR

Kyle Collins, BSC(Pharm), ACPR

Shaylee Peterson, BSc(Pharm), ACPR

Kieran Shah, BSC(Pharm), ACPR

Doctor of Pharmacy students

Sam Louie, BSc (Pharm)

Adjunct Professor

Faculty of Pharmaceutical Sciences

University of British Columbia

Vancouver, British Columbia

Competing interests: None declared.

The Pro and Con articles for this issue's "Point Counterpoint" column were developed from a debate held in fall 2015 as part of the course "Advanced Pharmacy Administration: Topics in Contemporary Practice" , Doctor of Pharmacy program, Faculty of Pharmaceutical Sciences, The University of British Columbia.

\section{CISADL 2015}

\section{Order your copy of the 2015 Canadian Investigational \& Special Access Drug List today!}

\section{Please use the CSHP order form found online at CSHP.ca to place your order:}

\section{http://www.cshp.ca/productsServices/otherPublications/canadianInvestigational_e.asp}

The CISADL is a compilation of drugs that are currently not marketed in Canada and may have Investigational or Special Access status with Health Canada. This list is not endorsed by Health Canada's Special Access Program. For precise information about the regulatory status of a drug, contact the Special Access Program directly. Entries to the list are contributed to by several Drug Information Centers across Canada and by Canadian drug manufacturers. In cases where non-marketed drugs do not appear on the list, foreign references should be consulted. The content of the list includes generic name and strength/concentration, dosage form, pharmacology/therapeutic use, trade and code name, source (manufacturer/distributor), and comments. Available in English only.

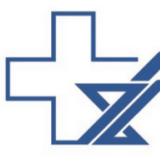
Société canadienne des pharmaciens d'hôpitaux 